\title{
Effect of road salt application on soil conductivity in Canmore, Alberta
}

\author{
Michael Zima
}

This study was conducted under the supervision of Professor Aaron Berg, Department of Geography, College of Social and Applied Human Sciences, University of Guelph

\begin{abstract}
Road salting is a wide-spread practice employed to increase driver safety during the winter months. Salt is, however, very mobile in the environment, toxic to some vegetation and invertebrates in high concentrations, and can seep into aquifers through groundwater recharge. Conductivity of roadside soils was measured as an estimate of soil salinity on the Trans-Canada Highway running through Canmore, Alberta on four consecutive days. Road size and elevation above the surrounding topography were deduced as key factors in determining where highest conductivity was found. Using a cubic polynomial equation for regression, peak conductivity values were estimated to occur at $12.1 \mathrm{~m}$ from the edge of the highway. Levels as measured from August 29th to September 1st 2011 demonstrated that soils were weakly to moderately saline. Although excessive soil salinity may be an issue following the spring melts, levels measured at this time of year were not considered to be of any significant environmental concern.
\end{abstract}

$\mathrm{T}_{\mathrm{D}}$ ransportation is a vital component of modern society. Dependency on the movement of people and goods has increased drastically in the last century - it is an essential aspect of every-day life. In temperate regions, winter brings forth decreased temperatures and freezing precipitation which considerably reduce traction for vehicles. A variety of methods are used to maintain roads in an attempt to increase safety for motorists. Authorities responsible for road maintenance make use of salts, brines, and sands to mitigate these hazards. The industrialized production of salt has made the substance abundant and affordable and it is thus used in various manners to increase road traction, by lowering the freezing point of water and delaying the onset of ice formation. Unfortunately, these practices cause unfavourable environmental effects. When aqueous, salt is highly mobile, leading to advective and diffusional transport away from the source, potentially resulting in saline groundwater recharge [1]. Since the contamination does not operate as a point source, and rather a "line source" [2], characterizing potential environmental impacts can be a complex process. This denotes serious implications for water quality as contamination in both ground and surface waters may be quite difficult to model.

Researching the dynamics of salt runoff from roadways is an excellent demonstration of the importance in understanding how humans affect the biophysical environment. Although effective techniques for managing our transportation needs in the winter have been developed, it is critical to be aware of the ways in which both biotic and abiotic systems are altered. Once an understanding of the mechanisms at work is established, there is a greater capacity for improving these techniques so that more sustainable practices are implemented.

The need for better understanding is given greater context when looking specifically at Canmore, Alberta. In their Environmental Sustainability Action Plan, the Town of Canmore presents a "desired future state", in which limited harmful compounds are used in municipal operations. Where alternatives are available, the town strives to opt for substances that are natural and non-toxic [3]. The importance of this motive is well-exemplified through local geological analyses; the Alberta Geological Survey reports that the Bow River floodplain is composed of Quaternary-period sediment deposits including combinations of till, alluvium, colluvium, gravel, sand and silt [4]. This makes for an active hydrogeological setting with significant interaction between surface waters and groundwater [5]. Additionally, regional concerns for water as a dwindling resource are on the rise in the wake of intensified climate change, due to the fact that alpine biomes are especially vulnerable [6]. Maintaining the quality of existing freshwater resources is thus paramount. Mason et al. (1999) state that when point sources of salt are eliminated, environmental concentrations usually decrease back to pre-usage levels as a result of their mobile nature [7]. Consequently, any research focused on investigating how salt manifests itself in a road-side environment is practically valuable for potential mitigation initiatives. 
The aim of the research was to investigate the spatial distribution of salt in road-side soils to determine if defined accumulation patterns were present. This study asks, (1) "Is road salting along the Trans-Canada Highway (TCH) in Canmore playing a significant role in the chemical alteration of adjacent soils?" and (2) "Is it possible to predict where the highest concentrations will be located in relation to the road surface so that we can better mitigate the environmental effects?"

Assuming consistent physical soil properties, it is hypothesized that larger roads cause greater salinity in adjacent soils, as more salt is likely to be applied and washed away. In this case, larger roadways would constitute a heavier burden in the immediate ecological vicinity.

\section{LITERATURE REVIEW}

Previous research regarding salinity in Banff National Park (northwest of Canmore) has indeed shown that human activity is affecting salinity in sensitive glacial rivers such as the Bow. For example, sodium and chloride concentrations, mainly attributed to road salt application, average up to 4 times higher at the eastern boundary of Banff National Park than just upstream (about $60 \mathrm{~km}$ ) at Lake Louise [8]. More importantly, Schindler (2000) found that there was a significant increase in salt levels measured downstream of Canmore as compared to upstream concentrations; this clearly exemplifies human culpability [8].

De-icing agent storage is also a leading factor of contamination. High salt levels in groundwater can usually be traced through well monitoring and field testing back to the source [9]. It is estimated that at least $0.3 \%$ of the total stored mass of de-icing agents leach every year, and hence groundwater quality near storage facilities can be significantly impacted [9]. Even after such point sources are eliminated, their environmental presence remains substantial for up to five years [9]. A recent study by the USGS suggests that fluvial chloride levels exceed EPA chronic toxicity thresholds in $100 \%$ of urban watercourses of south-east Wisconsin [10].

In aquatic environments, some invertebrates show severe impairment at acute saline exposures of $10 \mathrm{~g} / \mathrm{L}$. Various species in the Gammarus genus (amphipod crustaceans) exhibit major issues with mobility when exposed to such concentrations in only a short time [11]. Increased salinity in rivers has also been identified as a major stressor for aquatic insects, as noted by a significant loss in diversity [12].

Terrestrial vegetation is also significantly affected by increased salt usage. The collective outcome of road salting in the Banff area has created prevalent localized damage to roadside soils and conifers [13][14]. These trends have been noted extensively along the TCH corridor, but have also been found on secondary roads [13]. Other ecological effects for flora consist of stunted flower growth and dehydration from osmotic forces [15]. In coniferous ecosystems similar to the region in which Canmore is located, the application of road salt can have dramatic consequences for the species composition at high proximity to roadways [16] - this occurs as a result of drastic change in the chemical properties of soil, all incurred by increased salinity. Another study by the USGS explains that a major mechanism for salinity-related plant die offs is the restriction of nutrient uptake, as major cations are less available due to the increased presence of sodium and chloride [17]. It is also interesting to note that some invasive species, such as giant reed plants (Phragmites), are much more resistant to saline environments than native plants and will often out-compete them for water and nutrients [18].

As salt accumulates in melt pools at the onset of spring, ungulates have been found to roam alongside highways in search of briny waters. Through adaptive measures, many species have learned that where natural salt licks are limited, roadways can provide an effective substitute to satisfy this nutritional requirement [19]. Consequently, a high number of roadkill incidents involving moose in both Ontario and Finland are attributed to increased roadside salt concentrations in the late winter and early spring [19]. Although less effective as a de-icing compound, calcium magnesium acetate (CMA) has been found to be much less attractive to ungulates in search of salt licks [20].

It is also important to be aware of the aqueous geochemical mechanisms associated with increased salinity. When salt concentrations rise in soil and aquatic environments, the chemical equlibria of most compounds are effectively altered. Mercury, for example, readily dissociates from organic complexes within the sediment substrate in increasingly saline environments [21]. Heavy metals like mercury bioaccumulate within organisms and are thus a severe threat to aquatic and soil-based life forms. Norrström (2005) found that although lead is quite immobile in most soils, the accumulation of salt in roadside environments is so high that lead becomes mobilized and incorporated into groundwater recharge through colloid-assisted transport [22]. Zinc has also been noted to have increased mobility [23], while potassium, magnesium, and calcium tend to increase in concentration with chloride [7].

Evidently, abundant research has been done to determine typical chemical and biological effects of road salting. However, until recently, little had been done to specifically spatially characterize the saline nature of soils near a line source such as the TCH - Olofsson and Lundmark (2009) and Zehetner et al. (2009) provide the few exceptions to this. These two studies were completed in Sweden [24] and Austria [25], respectively, and there have been no such notable spatially quantitative analyses of salinity in or near Banff National Park - or even in Canada for that matter. Olofsson and Lundmark (2009) installed permanent electrodes at varying depths and distances from a motorway. Monthly measurements of resistivity were taken to distinguish between natural variations and those from road salt inputs. Zehetner et al. (2009) completed a similar study 


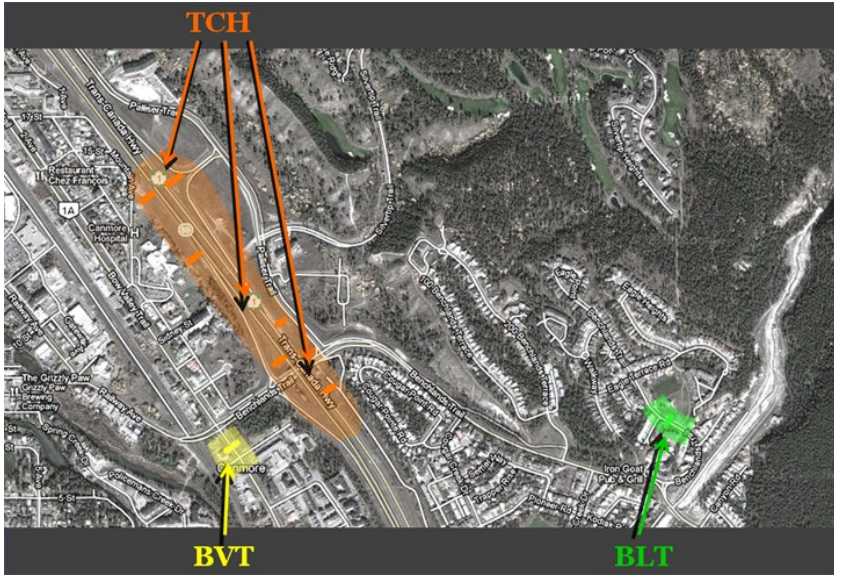

Figure 1. Map of east Canmore showing the locations of TransCanada Highway (TCH), Bow Valley Trail (BVT), and Benchlands Trail (BLT) measurement sites

on a smaller roadway; this was done by analyzing soil samples for road salt residues. They found an exponentiallike decrease in salt content with distance from the road. The design of a similar experiment in Canmore, Alberta, as demonstrated in this study, utilized some comparable methods.

\section{Methods AND EXPERIMENTAL DESIGN}

Although there are a number of possible techniques for determining salinity in the soil, measuring conductivity was ideal for two reasons. Firstly, conductivity is known as an

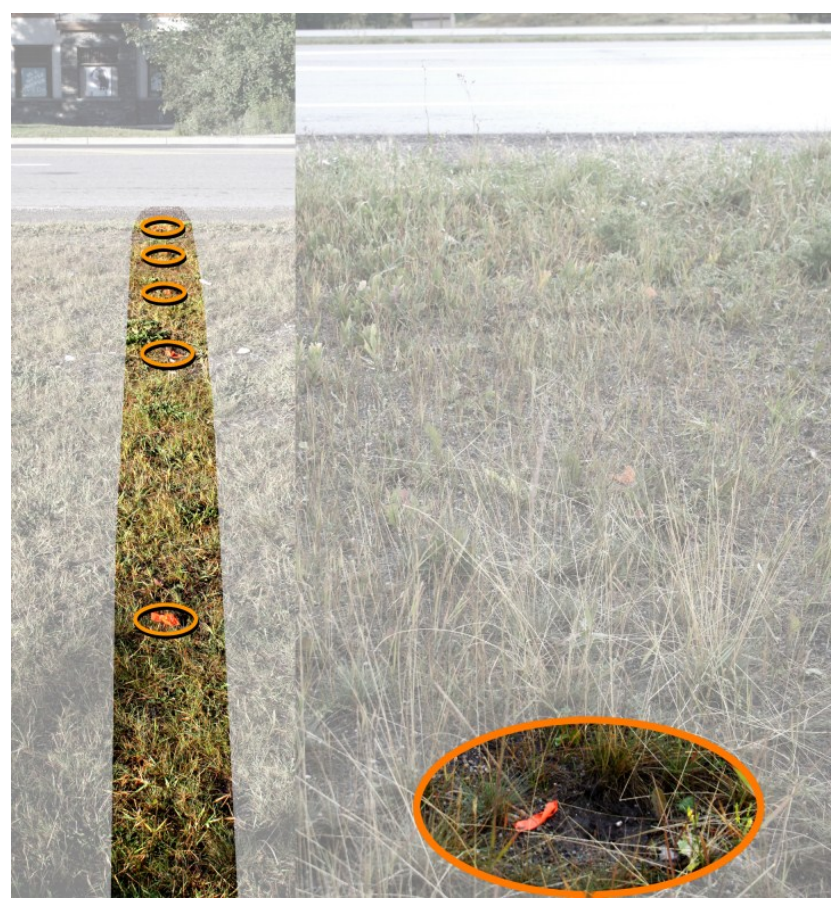

Figure 2. Image showing a typical transect with sampling points - note there are proportionally more closer to the roadway accurate estimate of ionic strength in a soil solution through the equation $I=0.013 \omega$, where ' $I$ ' is ionic strength in $\mathrm{mol} / \mathrm{L}$ and ' $\omega$ ' is conductivity in $\mathrm{S} / \mathrm{m}$ [26]. The constant may vary slightly when site-specific experiments are conducted. Ionic strength is then linked to the concentration of ions in the soil solution through the equation $I=1 / 2 \Sigma\left(\mathrm{c}_{+} \mathrm{Z}_{+}^{2}+\mathrm{c}_{-} \mathrm{z}_{-}^{2}\right)$, where $\mathrm{c}_{+}$ and $c$. are the concentrations of cations and anions, respectively, while $z_{+}$and $z_{-}$are the cationic and anionic valencies, respectively [27]. So a higher concentration of $\mathrm{Na}^{+}$ and $\mathrm{Cl}^{-}$caused by increased road salt application would yield greater ionic strength, and hence higher conductivity. Although this relationship is not perfectly correlated, it serves as an effective approximation [26]. Secondly, the use of a portable conductivity probe allows for repeated and efficient in-situ measurements, without the need to sample soils, transport them, and analyze them in the lab. This allowed for more data points in the time allocated for sampling, and greater flexibility when making site visits. The probe used was a Hanna HI-98331 Direct Soil Conductivity Tester, which automatically calibrated conductivity readings depending on the temperature. It had a range of 0.00 to 4.00 $\mathrm{S} / \mathrm{m}$, a resolution of $0.01 \mathrm{~S} / \mathrm{m}$, and an accuracy of $\pm 0.05 \mathrm{~S} / \mathrm{m}$.

The location of the study was determined in a two-part process. Before arriving on site, satellite pictures were surveyed to designate three general road categories for sampling. The first was the TCH - this was the main target of the study as it was presumed that the highest conductivity levels would be found here. The second division was for major municipal roads, so that conductivity levels in town could be compared to those measured on the TCH. Main roads in Canmore which fit this criterion were Bow Valley Trail and Railway Avenue. Lastly, a control site was sought. Residential neighbourhoods worked well with this stipulation because, according to municipal salting routes for Canmore, they had a lower salt application rate. Residential neighbourhoods near the downtown area appeared suitable, as well as the Benchlands Trail and Three Sisters communities.

Once on site in Canmore, these prospective sites were visited and assessed for adequacy. The main criteria considered were accessibility, practicality (sites not excessively distant from each other), transect length (long enough to get sufficient sampling points), soil variability (uniform enough along the entire transect), and topography (as flat as possible). Figure 1 shows the layout for all sampling sites; measurements for the "major municipal road" classification were carried out on Bow Valley Trail (BVT), and "control" measurements were completed on Benchlands Trail (BLT). One transect was designated for each side of the road at the BVT and BLT sites. For the TCH site, three transects were selected for each side of the road. This was done so that variability between sites along the TCH could be examined. It should be noted that TCH transects were not aligned directly across from each other - this was due to the site criteria as described above. However, transects were 


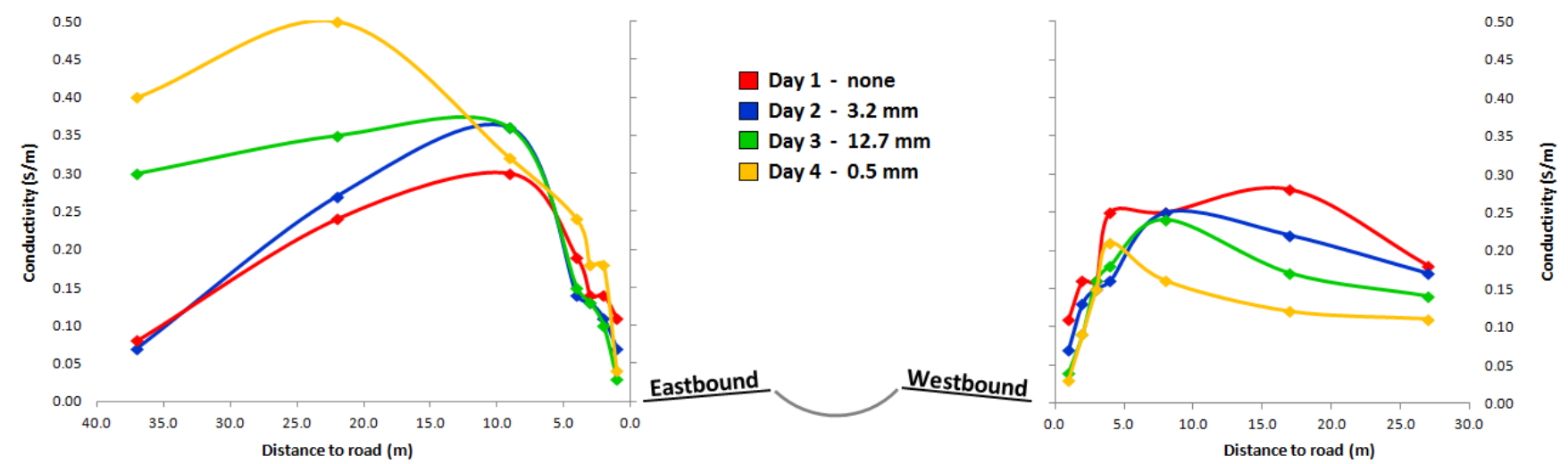

Figure 3. Trans-Canada Highway conductivity levels as measured at the same two transects over four days - amount of precipitation is shown for each day.

grouped as north/south pairs for simplification during graphical analyses.

Once transects were selected, sampling points were designated and marked with fluorescent ribbons. This was done in such a manner that sampling point density was highest near the road (see Figure 2). As shown in other literature [24][25], the largest gradient in salt content is quite proximal to the road surface; by placing more sampling points closer to the road, changes in conductivity as a function of distance from the road's edge could be noted with greater precision.

Before visiting each site, the conductivity meter was calibrated in a Milwaukee $1.413 \mathrm{~S} / \mathrm{m} \mathrm{KCl}$ solution standard. When taking measurements, a spade was used to homogenize the top $10 \mathrm{~cm}$ of the soil. Although an ideal analysis would have measured the conductivity of soil horizons below the surface as well, the soil layer near some road surfaces was not thick enough to do so. If the surface was too dry to insert the probe, the soil was saturated with water. The conductivity of this water was measured to be below the resolution of the probe, and thus it did not affect readings in the soil. For each sampling point, multiple readings were taken, ensuring that the value obtained was consistent. These values were recorded for each transect, at each site, for each of the four sampling days (August 29th to September 1st).

Although the primary objective was rooted in spatial analysis, daily repeated sampling procedures took place for four days. This coincided with a major precipitation event (29-Aug: 0.0mm; 30-Aug: $3.2 \mathrm{~mm}$; 31-Aug: $12.7 \mathrm{~mm}$; 1Sep: $0.5 \mathrm{~mm}$ ) which took place following a two-week drought [28]. This allowed for an investigation into the temporal variability associated with heavy rains and consequent leaching.

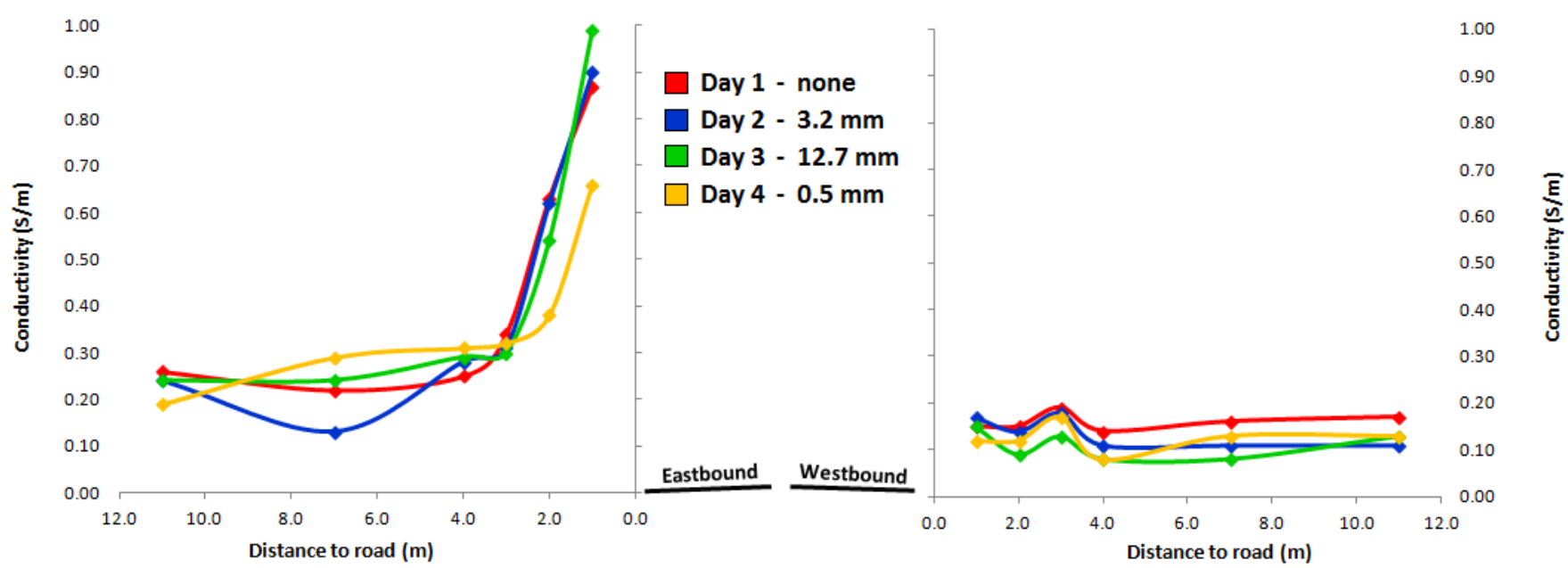

Figure 4. Bow Valley Trail conductivity levels as measured at the same two transects over four days - amount of precipitation is shown for each day 


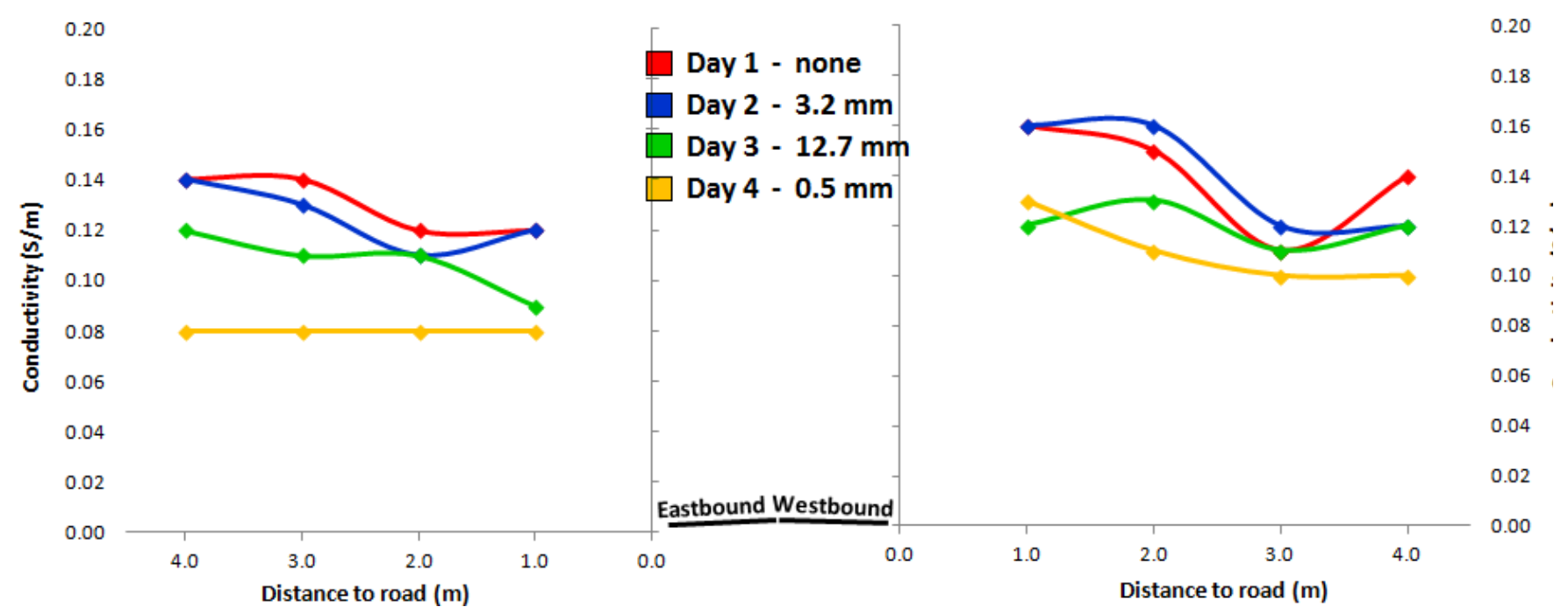

Figure 5. Benchlands Trail conductivity levels as measured at the same two transects over four days - amount of precipitation is shown for each day

\section{RESULTS}

\section{Trans-Canada Highway (TCH)}

Conductivity levels at the road's edge were quite low, but increased sharply with distance (see Figure 3) for the first 5 to $10 \mathrm{~m}$. Conductivity generally peaked around $10 \mathrm{~m}$ from the road surface, and gradually declined as distance increased. On the south side of the TCH, peak levels were found between 0.30 and $0.35 \mathrm{~S} / \mathrm{m}$, while on the north side they peaked around $0.25 \mathrm{~S} / \mathrm{m}$. Over the four-day period, there were no drastic shifts in the conductivity trends with distance. Measurements on days three and four (green and yellow curves, respectively, in Figure 3) for the south transect, however, showed non-conforming elevated values at 22 and $37 \mathrm{~m}$ from the road. On these days, the specific sampling points were located in an area of standing water.

\section{Bow Valley Trail (BVT)}

The two transects of BVT show quite different results (see Figure 4). On the north side, conductivity values are low at the road's edge and remain relatively unchanged with increasing distance from the road. There is a slight noticeable peak at $3 \mathrm{~m}$ from the road but otherwise, the majority of values are between 0.10 and $0.20 \mathrm{~S} / \mathrm{m}$. On the south transect, values at the road's edge are very high - the highest recorded value for the experiment was found here at $0.99 \mathrm{~S} / \mathrm{m}$. At $3 \mathrm{~m}$ from the roadside, the conductivity drops off rapidly. From the $3 \mathrm{~m}$ mark onwards, conductivity values remain steady between 0.20 and $0.30 \mathrm{~S} / \mathrm{m}$. For both north and south sides, there are no drastic changes in conductivity trends with distance over the four days.

\section{Benchlands Trail (BLT)}

Conductivity levels remain low on both the north and south transects, never exceeding $0.16 \mathrm{~S} / \mathrm{m}$. There are no evident peaks in the data or trends for conductivity with distance from the road's edge (see Figure 5). Over the four day period, there are no drastic shifts in the distribution of these values.

\section{Spatial Variability on the Trans-Canada Highway (TCH, TCH-West, TCH-East)}

Figure 6 shows three different transects for the TCH analyzed only on day four for spatial variability. The original TCH transect is used (yellow curve in Figure 3), in addition to two more transects - one east of the original (blue curve), and one west of it (maroon curve). The central TCH transect on the south side, as previously noted, has data points at 22 and $37 \mathrm{~m}$ from the road which were located in standing water. Otherwise, there was only a slight variation in the peak values for conductivity - they occurred approximately between 5 and $15 \mathrm{~m}$ from the roadway. As visible in Figure 6 , there is not a great deal of variation in the shape of the conductivity curves from the three pairs of transects, although this is much clearer on the north side than the south side.

\section{Non-Linear Regression as a Model}

Motulsky and Ransnas (1987) state that non-linear regression can only be used when there is no error in the measurements of the independent variable [29]. In this experiment, the conductivity probe has an accuracy of \pm 0.05 $\mathrm{S} / \mathrm{m}$ (dependent variable), but the measured distances to road (independent variable) had effectively zero error. As a result, 


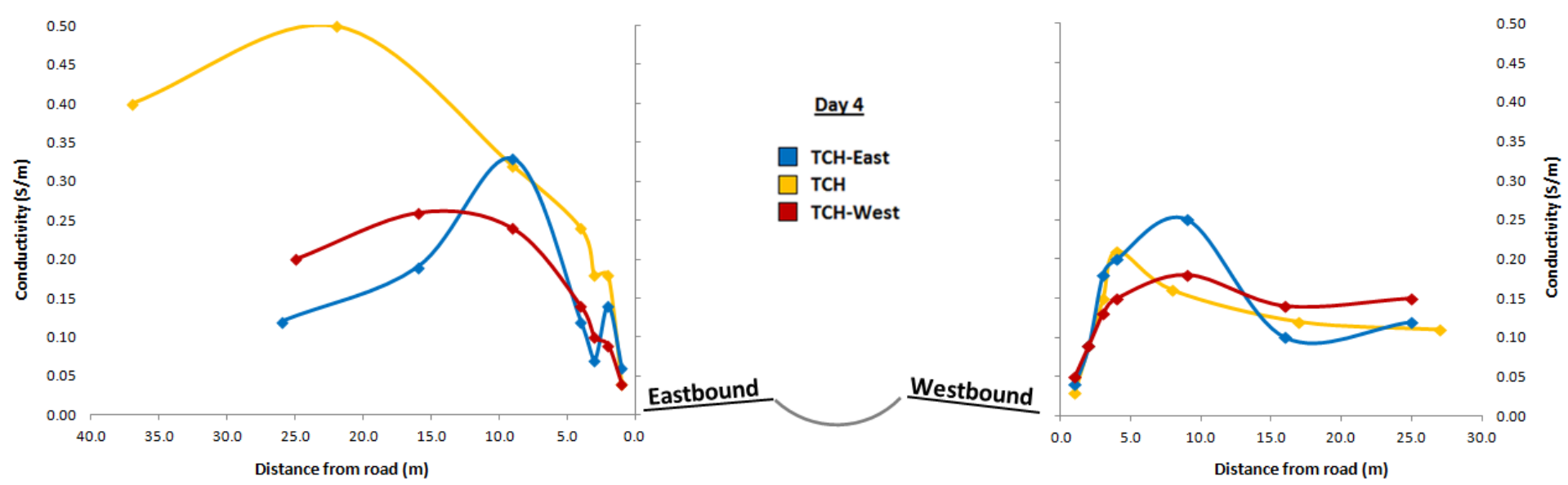

Figure 6. Trans-Canada Highway (yellow), TCH-East (blue), and TCH-West (maroon) conductivity levels as measured on day four

non-linear regression provided an effective tool for modelling conductivity levels.

Data from all transects of the TCH were compiled onto one graph to assess correlation - this includes north and south transects of the main TCH site for all four days (Figure 3 ), as well as the north/south transect pairs for TCH-East and TCH-West on day four (Figure 6), for a total of twelve transects. A scatter plot of all data points shows that the correlation between the independent and dependent variables is likely non-linear (see Figure 7). Conductivity values obtained at sampling points in standing water were removed from this analysis to improve correlation (see Discussion).

By utilizing non-linear regression in the form of a cubic polynomial equation (see Figure 7), one can make an estimation of where peak conductivity values will occur in relation to the roadway. Through an iterative process, the cubic equation $\mathrm{y}=0.0000334 \mathrm{x}^{3}-0.00231 \mathrm{x}^{2}+0.0415 \mathrm{x}+$ 0.0358 is formulated, and a peak expected value of 0.257 $\mathrm{S} / \mathrm{m}$ is obtained at a distance of $12.1 \mathrm{~m}$ from the road. This is accompanied by an $\mathrm{R}^{2}$-value of 0.6058 , compared to only 0.0415 for a simple linear regression.

\section{DiscuSSION}

Conductivity levels appear to be highest on the $\mathrm{TCH}$, followed by BVT, and then BLT, at which the measurements are presumed representative of background levels in the area. Conductivity seems to be positively correlated with road size, as multi-lane highways are likely to experience greater salt application than main roads and residential streets. According to the cubic polynomial regression model for the $\mathrm{TCH}$, peak conductivity values for the specific conditions and time of year can be estimated at $0.257 \mathrm{~S} / \mathrm{m}, 12.1 \mathrm{~m}$ from the road's edge. The non-linear approximation is much better than the linear one, yielding an $\mathrm{R}^{2}$-value of 0.6058 , but this could be reasonably deduced simply by visually inspecting the scatter plot. The second point of inflection for the cubic function occurs at $34.7 \mathrm{~m}$, indicating that this model is only applicable for distances up to $34.7 \mathrm{~m}$ from the road (see Figure 7).

The Alberta Ministry of Agriculture and Rural Development (ARD) provides soil salinity ratings based on in-situ electrical conductivity values to categorize plant tolerance of salt-affected soils. For soil depths up to $60 \mathrm{~cm}$, 0.2 to $0.4 \mathrm{~S} / \mathrm{m}$ is classified as "weakly saline" while 0.4 to $0.8 \mathrm{~S} / \mathrm{m}$ is classified as "moderately saline" [30]. In comparing values obtained for this study, the majority of tested soils fall under the "weakly saline" category. Considering the fact that these measurements were taken in late August and early September, the same locations would likely be classified as "strongly saline" in the early spring following snowmelt, as high concentrations of salt from runoff would be entering the soil and causing potentially toxic conditions [30]. The fact that salinity can still be measured in the late summer indicates that road salt has a year-round presence, even though it is only applied for a few months in the winter.

On days three and four, the south transect for the TCH site had standing water at 22 and $37 \mathrm{~m}$ from the roadway as a result of heavy rains. These points were removed from the regression model because of abnormally elevated conductivity values, as the sampling points were underwater. This may infer that the heavy rains elevated the water table to the surface. Because groundwater becomes more saline than surface water as a result of high anthropogenic extraction [31] (as in Canmore), it is also possible that these conductivity measurements were not representative of the true soil salinity.

For the south transect on BVT, abnormally high conductivity was discovered within the first $2 \mathrm{~m}$ from the roadway on all four days. This infers that (1) there may have been an unusually large amount of salt-concentrated 


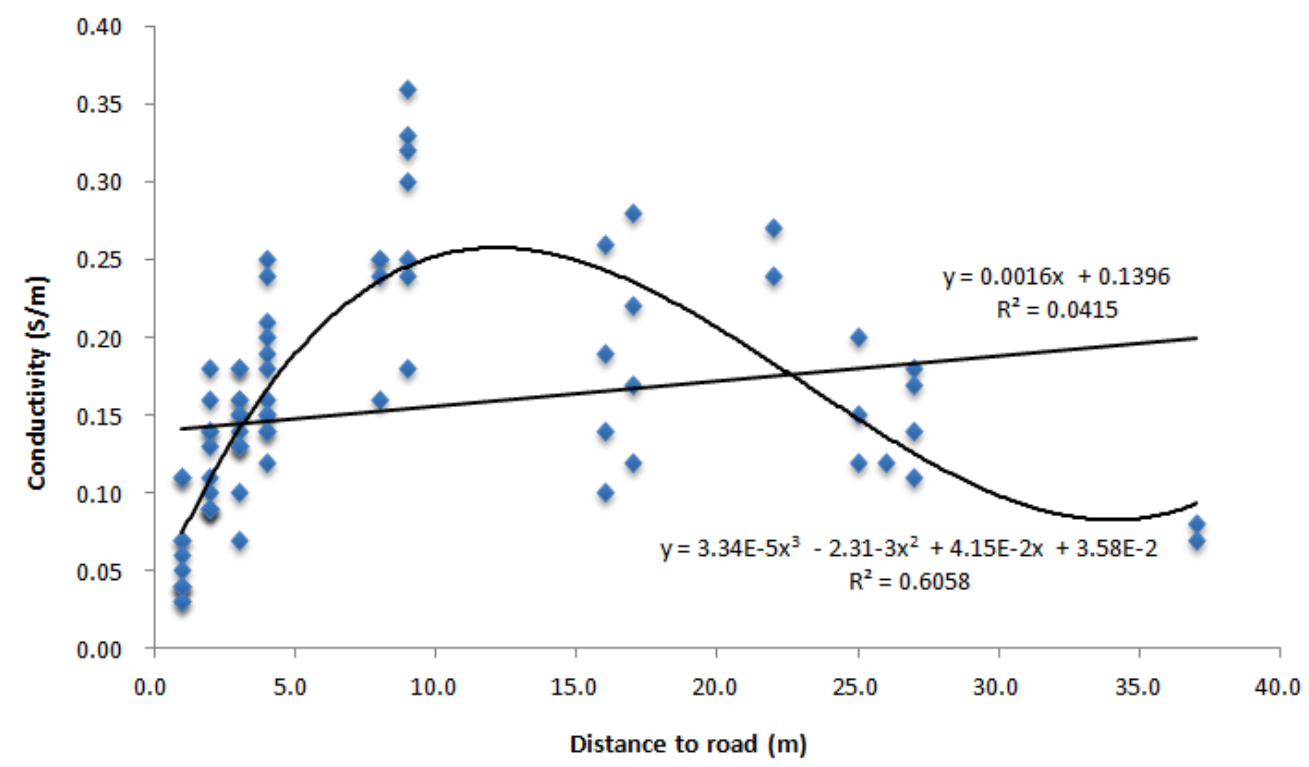

Figure 7. Comparison of linear and non-linear (cubic polynomial) regression methods for Trans-Canada Highway data points

snowmelt, (2) leaching of the salts was being restricted causing accumulation, or (3) an external factor other than chemical composition of the soil was causing increased conductivity (e.g. metallic object, live underground wires).

Across the three pairs of transects on the TCH, no major differences were noted in the shape of the conductivity curves (see Figure 6). Had this experiment been repeated with more data points and yielded a similar result, it could be argued that these conductivity patterns were expected for the entire stretch of the TCH through Canmore, assuming similar soil physics, hydrogeology, and road layout (an unlikely scenario).

The high variability in precipitation and soil moisture over the four-day period allowed for an analysis of how conductivity levels change after rain. The fact that the conductivity levels did not change significantly with distance over the four days implies that (1) the heavy rainfall did not notably contribute to increased leaching, or (2) salt concentrations had reached steady-state conditions, where increased leaching did not draw more salt downwards. Although the precipitation had a limited effect on salinity at the surface, the rain events would have likely increased the downward leaching of salts in deeper soil horizons.

In referring back to the research objectives of this study, it seems as though road salting is not having yearround deleterious effects on adjacent soils. This may be likely, however, during the spring melt period when salt runoff is highest - this would have to be verified through similar research at that time of year. It is important to note that increased salt concentrations are indeed being noted next to roadways well beyond the spring melt period. With sufficient data, it appears possible to predict where peak salinity will occur in relation to the road's edge with the use of non-linear regression. As wider roads do seem to have a greater effect on soil salinity from increased salt application, the hypothesis is justified.

\section{CONCLUSION}

Using conductivity as an estimate of soil salinity generated by road salting is an efficient and cost-effective method. Estimating the amount of salinity generated as well as the location of highest concentration is very dependent on the road size and design. A cubic polynomial function was used to estimate peak conductivity alongside the TCH in Canmore, Alberta and produced a value of $12.1 \mathrm{~m}$ from the roadway. A study in Sweden on a large motorway similar in size to the TCH found lowest resistance (peak conductivity) around $5 \mathrm{~m}$ from the roadway [24]. In addition, an Austrian study on a smaller roadway found peak chloride levels within 1-2 m of the road's edge [25]. This aligns well with a model (see Figure 8) adapted from dispersion mechanisms presented by Labadia and Buttle (1996), which shows that larger, more elevated roadways will have accumulation of snow and meltwater further from the edge of the road, where the slope levels out [1]. This assumes the soil is physically uniform, as increased complexity of such a system makes it much harder to predict dispersion dynamics. Although salinity was only investigated at the soil surface, it would have been very useful to also examine deeper soil horizons (1-2 $\mathrm{m}$ in depth) as done by Olofsson and Lundmark (2009).

Understanding how salt accumulates alongside roadways has noteworthy implications on watershed management techniques. The mobile nature of salt makes it a difficult environmental contaminant to manage. From roadways, it runs off rapidly in surface waters affecting nearby aquatic habitats and can easily infiltrate aquifers, causing regional issues for drinking water. Having the ability 

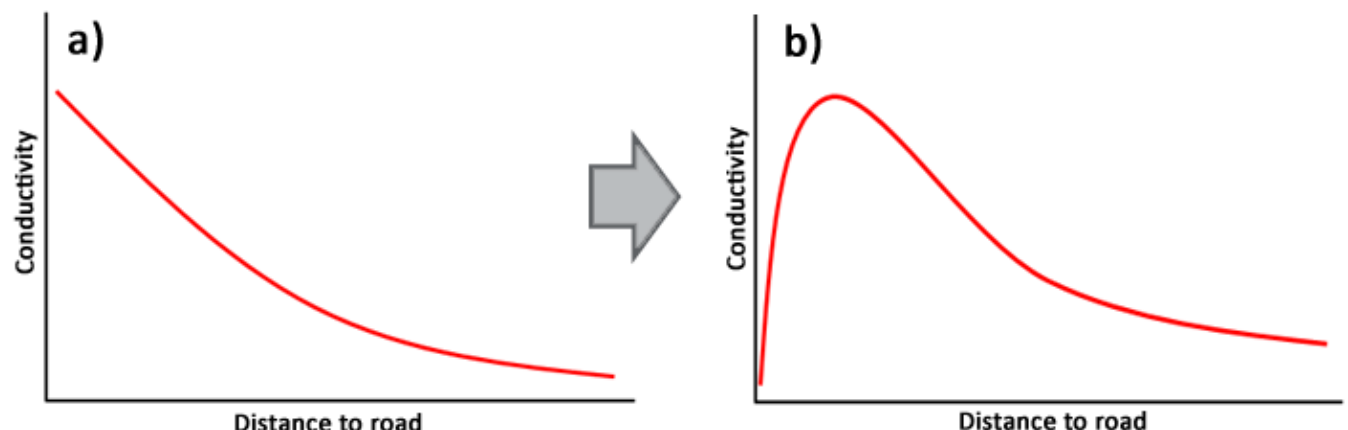

Figure 8. Comparison of conductivity curves for (a) a smaller/level roadway and (b) a larger/elevated roadway; adapted from mechanisms presented in Labadia and Buttle (1996)

to pinpoint where salinity is highest after a spring melt can benefit engineering initiatives for runoff treatment. Further research should be done regarding potential effectiveness of these kinds of projects. Knowledge of salinity accumulation patterns is also critical for planting appropriate plant species. By ensuring roadside plants are sufficiently salt-tolerant, vegetation die offs are limited, thus ensuring proper soil retention, mitigation of erosion, and increased natural treatment of saline waters. Due to the extensive safety benefits of road salting, it seems exceedingly unlikely that the practice will desist in the near future. The extensive development of natural or engineered attenuation systems is consequently highly recommended.

\section{ACKNOWLEDGEMENTS}

The author would like to thank Dr. Aaron Berg from the University of Guelph Department of Geography for his direction and advice during the field sampling period, as well as his assistance in editing the paper. Expenses for the field trip were partially covered by the Arthur D. Latornell Travel Grant.

\section{REFERENCES}

1. Labadia CF, Buttle JM. 1996. Road Salt Accumulation in Highway Snow Banks and Transport Through the Unsaturated Zone of the Oak Ridges Moraine, Southern Ontario. Hydrological Processes 10: 1575-1589.

2. Briggs DJ, de Hoogh C, Gulliver J, Wills J, Elliott P, Kingham S, Smallbone K. 2000. A regression-based method for mapping traffic-related air pollution: application and testing in four contrasting urban environments. Science of the Total Environment 253(13): 151-167.

3. Town of Canmore. 2005. Environmental Sustainability Action Plan. Toxics Reduction - Desired Future State.

4. Hamilton WN, Price MC, Chao DK. 1998. Geology of the Bow River Corridor. Alberta Geology Survey Resource Data Division.
5. Winter TC, Harvey JW, Frenke OL, Alley WM. 1998. Ground Water and Surface Water: A Single Resource. US Geological Survey Circular 1139.

6. McCarthy JJ, Canziani OF, Leary NA, Dokken DJ, White KS. 2001. Climate Change 2001: Impacts, Adaption, and Vulnerability. Third Assessment Report - WGII.

7. Mason CF, Norton SA, Fernandez IJ, Katz LE. 1999. Deconstruction of the Chemical Effects of Road Salt on Stream Water Chemistry. Journal of Environmental Quality 28(1): 82-91.

8. Schindler DW. 2000. Aquatic Problems Caused by Human Activities in Banff National Park, Alberta, Canada. AMBIO: A Journal of the Human Environment 29(7): 401-407.

9. Ostendorf DW, Hinlein ES, Rotaru C, DeGroot DJ. 2006. Contamination of Groundwater by Outdoor Highway Deicing Agent Storage. Journal of Hydrology 326(1-4): 109-121.

10. Corsi SR, Graczyk DJ, Geis SW, Booth NL, Richards KD. 2010. A Fresh Look at Road Salt: Aquatic Toxicity and Water-Quality Impacts on Local, Regional, and National Scales. Environmental Science and Technology 44(19): 7376-7382.

11. Blasius B, Merritt RW. 2002. Field and Laboratory Investigations on the Effects of Road Salt $(\mathrm{NaCl})$ on Stream Macroinvertebrate Communities. Environmental Pollution 120(2): 219-231.

12. Demers CL. 1992. Effects of Road Deicing Salt on Aquatic Invertebrates in Four Adirondack Streams. Chemical Deicers and the Environment: 245-251.

13. Blank M, Clevenger T. 2008. Improving the Ecological Function of the Upper Bow River: Bow Lake to Kananaskis Dam. Technical Report \#4. Canmore, AB.

14. Banff Warden Service. 1991. Road Salt Report. Banff National Park.

15. Berkheimer SF, Potter JK, Andresen JA, Hanson EJ. 2006. Flower Bud Mortality and Salt Levels in Highbush Blueberry Fields Adjacent to Michigan Highways Treated with Deicing Salt. Horticultural Technology 16(3): 382-83.

16. Bernhardt -Römermann M, Kirchner M, Kudernatsch T, Jakobi G, Fischer A. 2006. Changed Vegetation 
Composition in Coniferous Forests near to Motorways in Southern Germany: The Effects of Traffic-born Pollution. Environmental Pollution 143(3): 572-581.

17. Snodgrass JW, Lev SM, Casey RE, Landa ER. 2010. Final Technical Report of Activities Under Subaward Agreement Z592801: Integration of Stormwater Management Ponds into Urban Communities. US Geological Service.

18. Richburg JA, Patterson WA III, Lowenstein F. 2001. Effects of Road Salt and Phragmites Australis Invasion on the Vegetation of a Western Massachusetts Calcareous Lake-Basin Fen. Wetlands 21(2): 247-255.

19. Bruinderink G, Hazebroek E. 1996. Ungulate Traffic Collisions in Europe. Conservation Biology 10(4): 10591067.

20. Akbar KF, Headley AD, Hale WHG, Athar M. 2006. A Comparative Study of De-Icing Salts (Sodium Chloride and Calcium Magnesium Acetate) on the Growth of Some Roadside Plants of England. Journal of Applied Scientific Environmental Management 10(1): 67-71.

21. Feick G, Horne RA, Yeaple D. 1972. Release of Mercury from Contaminated Freshwater Sediments by the Runoff of Road Deicing Salt. Science 175(4026): 1142-1143.

22. Norrström AC. 2005. Metal Mobility by De-icing Salt from an Infiltration Trench for Highway Runoff. Applied Geochemistry 20: 1907-1919.

23. Ruth O. 2003. The Effects of De-icing in Helsinki Urban Streams, Southern Finland. Water Science and Technology 48(9): 33-43.

24. Olofsson B, Lundmark A. 2009. Monitoring the Impact of De-icing Salt on Roadside Soils with Time-lapse
Resistivity Measurements. Environmental Geology 57(1): 217-229.

25. Zehetner F, Rosenfellner U, Mentler A, Gerzabek MH. 2009. Distribution of Road Salt Residues, Heavy Metals and Polycyclic Aromatic Hydrocarbons across a Highway-Forest Interface. Water, Air, and Soil Pollution 198: 125-132.

26. Griffin RA, Jurinak JJ. 1973. Estimation of ActivityCoefficients from Electrical Conductivity of Natural Aquatic Systems and Soil Extracts. Soil Science 116(1): 26-30.

27. Lewis GN, Randall MJ. 1921. The Activity Coefficient of Strong Electrolytes. Journal of the American Chemical Society 43: 1112-1154.

28. Environment Canada. 2011. Daily Data Report for August 2011 in Banff, AB. National Climate Data and Information Archive.

29. Motulsky HJ, Ransnas LA. 1987. Fitting Curves to Data Using Non-linear Regression: A Practical and Nonmathematical Review. Federation of American Societies for Experimental Biology Journal 1: 365-374.

30. Alberta Ministry of Agriculture and Rural Development (ARD). 2001. Salt Tolerance of Plants. $<$ http://www1.agric.gov.ab.ca/\$department/deptdocs.nsf/ all/agdex3303>.

31. Van Weert F, van der Gun J, Reckman J. 2009. Global Overview of Saline Groundwater Occurrence and Genesis. International Groundwater Resources Assessment Centre. 